\title{
Age and Gender Difference of Typhoid Fever among Paediatric Patients Attended at a Tertiary Care Hospital in Bangladesh
}

\author{
AFM Arshedi Sattar ${ }^{1}$, Mohammad Shah Jahirul Haque Chowdhury ${ }^{2}$, Md. Abdullah Yusuf ${ }^{3}$, Sabina Jesmin $^{4}$, \\ Showkot Ara ${ }^{5}$, Md. Badrul Islam ${ }^{6}$ \\ ${ }^{1}$ Assistant Professor, Department of Microbiology, National Institute of Neurosciences \& Hospital, Dhaka, Bangladesh; ${ }^{2}$ Associate \\ Professor, Department of Clinical Neurology, National Institute of Neurosciences \& Hospital, Dhaka, Bangladesh; ${ }^{3}$ Assistant \\ Professor, Department of Microbiology, National Institute of Neurosciences \& Hospital, Dhaka, Bangladesh; ${ }^{4}$ Assistant Professor, \\ Department of Pharmacology, National Institute of Neurosciences \& Hospital, Dhaka, Bangladesh; ${ }^{5}$ Assistant Professor, Department \\ of Radiology \& Neuroimaging, National Institute of Neurosciences \& Hospital, Dhaka, Bangladesh; ${ }^{6}$ Associate Professor, \\ Department of Microbiology, Dhaka National Medical College, Dhaka, Bangladesh
}

[Received: 10 January 2016; Revised: 12 March 2016; Accepted: 26 October 2016; Published: 1 December 2016]

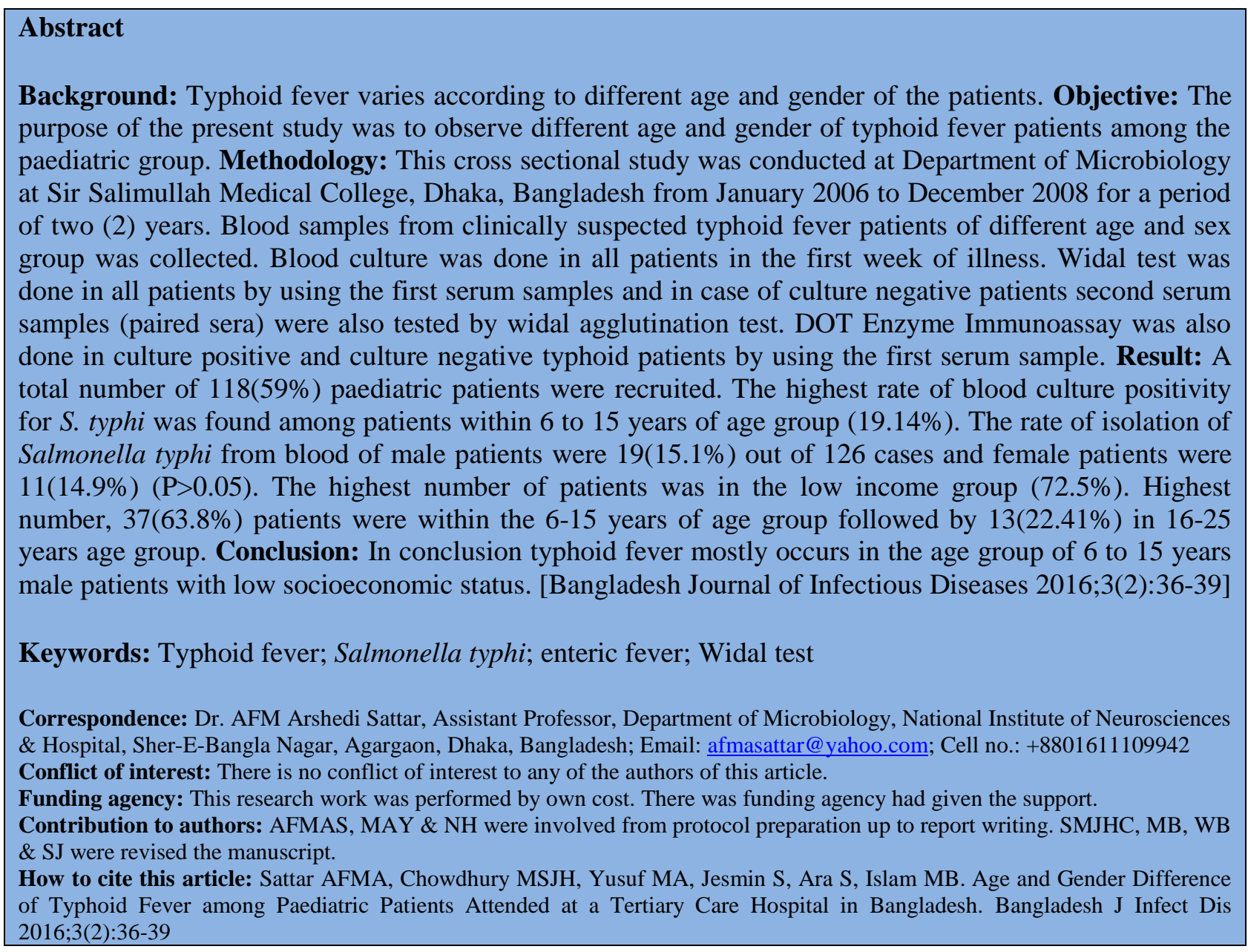




\section{Introduction}

Typhoid fever is a systemic infectious disease of the reticulo-endothelial system characterized by an acute illness ${ }^{1}$. The first typical manifestations are fever, headache, abdominal pain, relative bradycardia, splenomegaly, and leukopenia ${ }^{2}$. It is a life-threatening illness caused by Salmonella enterica subspecies enterica serotype typhi ${ }^{3}$.

It is distributed worldwide. Typhoid fever was an important cause of illness and death in the overcrowded and unsanitary urban conditions of the United States and Europe in the $19^{\text {th }}$ century ${ }^{4}$. From a study by WHO, there was 16.6 million cases of typhoid fever in all around the world with a 60,000 deaths in each year ${ }^{5}$. In the United States, 2445 cases were reported to the Centers for Disease Control and Prevention between 1985 and 1994, $72 \%$ of which were imported while traveling internationally, most frequently from Mexico or India ${ }^{6}$. The provision of clean water and good sewage systems led to a dramatic decrease in the incidence of typhoid in these regions. Despite its diminishing incidence in the United States and Europe, typhoid fever remains a major cause of illness in many parts of the developing world with an estimation of 12.5 million cases each year ${ }^{7}$. It is endemic in many developing countries particularly in Indian subcontinent, South and Central America, the most part of sub-Saharan Africa and also Southeast Asia ${ }^{8}$. It is also a major public health problem in developing countries like Bangladesh ${ }^{9}$. Reliable data from which to estimate the burden of disease in these areas are difficult to obtain, since many hospitals lack facilities for blood culture and up to $90.0 \%$ of patients with typhoid are treated as outpatients ${ }^{10}$. The purpose of the present study was to observe different age and gender of typhoid fever patients among the paediatric group.

\section{Methodology}

This cross sectional study was conducted at Department of Microbiology at Sir Salimullah Medical College, Dhaka, Bangladesh from January 2006 to December 2008 for a period of two years. Laboratory works were performed in Microbiology Department. A total number of 200 clinically suspected typhoid fever patients of different age groups who attended at the outdoor department (OPD) of Sir Salimullah Medical College, Dhaka and Dhaka Medical College, Dhaka, were included in this study. All patients who have high grade of temperature for more than 4 days and a clinically suspicion of typhoid fever were included in this study. Patients taking antibiotics prior to come to outdoor department (OPD) and patients having others diagnosed febrile diseases were excluded from the study. Patients under therapy on immunosuppressive drugs were also excluded from this study. Blood was taken from each patient in the first week of illness from the 200 cases for culture and serological tests. A second blood sample was collected only from the culture negative patients 7 to 10 days after collection of the first blood sample to demonstrate rise in titre in Widal test. Verbal consents were taken from the patients or from their attendants before collection of samples. With all aseptic precautions, blood was collected from 200 patients. Blood culture was performed in conventional method. Suspected colonies were identified as Salmonella typhi by Gram stain and motility test followed by inoculation into Kligler Iron agar (KIA) and Motility Indole Urea (MIU) media. The suspected organisms were further confirmed by biochemical tests and by specific antisera. Widal agglutination test was done in all patients using the $1^{\text {st }}$ serum samples and in culture negative patients also using the $2^{\text {nd }}$ serum samples (Paired sera) and by rapid slide titration method, using stained febrile antigens (Plasmatec Laboratory products Ltd., UK) containing $\mathrm{O}$ and $\mathrm{H}$ antigens of Salmonella typhi and $\mathrm{O}$ and $\mathrm{H}$ antigens of Salmonella paratyphi A and B with serial dilutions of sera beginning at 1:20. Dot enzyme Immunoassay was done as per manufacturer's instruction using the $1^{\text {st }}$ serum samples from all groups of patients and controls.

\section{Result}

A total number of $118(59 \%)$ paediatric patients were recruited of which majority were in the age group of 6 to 15 years which was 94(79.7\%) cases followed by 2 to 5 years and 0 to 1 years which were $22(18.6 \%)$ cases and $2(1.7 \%)$ cases respectively (Table 1 ).

Table 1: Age Variation among the Study Populations $(\mathbf{n}=118)$

\begin{tabular}{lcc}
\hline $\begin{array}{l}\text { Age group } \\
\text { (Years) }\end{array}$ & Frequency & Percentage \\
\hline 0 to 1 & 2 & 1.7 \\
2 to 5 & 22 & 18.6 \\
6 to 15 & 94 & 79.7 \\
Total & $\mathbf{1 1 8}$ & $\mathbf{1 0 0 . 0}$ \\
\hline
\end{tabular}

The highest rate of blood culture positivity for $S$. typhi was found among patients within 6 to 15 years of age group which was $18(19.1 \%)$. In 2 to 5 years 
age group only $2(9.1 \%)$ cases were culture positive (Table 2).

Table 2: Age Variation according to Confirmed Typhoid Fever Paediatric Patients $(n=20)$

\begin{tabular}{lccl}
\hline Age Group & \multicolumn{2}{c}{$\begin{array}{c}\text { Confirmed Typhoid } \\
\text { Fever }\end{array}$} & \multicolumn{1}{c}{ Total } \\
\cline { 2 - 3 } & Positive & Negative & \\
\hline 0 to 1 Years & $0(0.0 \%)$ & $2(100.0 \%)$ & $2(100.0 \%)$ \\
2 to 5 Years & $2(9.1 \%)$ & $20(90.9 \%)$ & $22(100.0 \%)$ \\
6 to 15 Years & $18(19.1 \%)$ & $76(80.9 \%)$ & $94(100.0 \%)$ \\
Total & $\mathbf{2 0}(\mathbf{1 6 . 9 \% )})$ & $\mathbf{9 8}(\mathbf{8 3 . 1 \% )})$ & $\mathbf{1 1 8}(\mathbf{1 0 0 . 0 \% )})$ \\
\hline
\end{tabular}

Male was predominant than female which was $74(62.3 \%)$ cases and 44(37.3\%) cases respectively. The ratio of male and female was 1.7:1 (Table 3).

Table 3: Gender Difference among the Study Populations $(\mathbf{n}=118)$

\begin{tabular}{lcc}
\hline Gender & Frequency & Percentage \\
\hline Male & 74 & 62.7 \\
Female & 44 & 37.3 \\
Total & $\mathbf{1 1 8}$ & $\mathbf{1 0 0 . 0}$ \\
\hline
\end{tabular}

The rate of isolation of Salmonella typhi from blood of male patients were $19(25.7 \%)$ out of 74 cases and female patients were $11(14.9 \%)$. There is no significant $(\mathrm{P}>0.05)$ difference between male and female patients (Table 2).

Table 3: Rate of Positivity of Confirmed Typhoid Fever Patients according to Gender $(\mathbf{n}=118)$

\begin{tabular}{llll}
\hline \multirow{2}{*}{ Gender } & \multicolumn{2}{c}{ Salmonella typhi } & \multicolumn{1}{c}{ Total } \\
\cline { 2 - 3 } & Positive & Negative & \\
\hline Male & $13(17.6 \%)$ & $61(82.4 \%)$ & $74(100.0 \%)$ \\
Female & $7(15.9 \%)$ & $37(84.1 \%)$ & $44(100.0 \%)$ \\
Total & $\mathbf{2 0}(\mathbf{1 6 . 9 \%})$ & $\mathbf{9 8}(\mathbf{8 3 . 1 \%})$ & $\mathbf{1 1 8}(\mathbf{1 0 0 . 0 \%})$ \\
\hline
\end{tabular}

Out of 200 patients the highest number of patients was in the low income group which was $145(72.5 \%)$ cases and the number of patients was lowest in high income group which was $8(4 \%)$ cases (Table 3 ).

Table 3: Socioeconomic Status of the Study Populations $(\mathbf{n = 1 1 8})$

\begin{tabular}{lccl}
\hline $\begin{array}{l}\text { Income } \\
\text { group }\end{array}$ & Male & Female & \multicolumn{1}{c}{ Total } \\
\hline Lower & $87(43.5 \%)$ & $58(29 \%)$ & $145(72.5 \%)$ \\
Middle & $34(17 \%)$ & $13(6.5 \%)$ & $47(23.5 \%)$ \\
Higher & $5(2.5 \%)$ & $3(1.5 \%)$ & $8(4 \%)$
\end{tabular}

Bangladesh J Infect Dis

\begin{tabular}{llll} 
Total & 126 & 74 & 200 \\
\hline
\end{tabular}

\section{Discussion}

Typhoid fever is endemic in many developing countries particularly in the Indian subcontinent including Bangladesh ${ }^{11}$. It is a dreaded disease because of its long course if not detected $\&$ treated early and its associated complications ${ }^{12}$. There are reports of changing clinical features in typhoid fever caused by drug resistant organism ${ }^{13}$. This leads to difficulty in clinical diagnosis. The gold standard in the diagnosis of typhoid fever is the isolation of S. typhi from the patient's blood.

Human restricted Salmonella enterica serotype Typhi causes typhoid fever and globally more than 21 million cases of $S$. Typhi infection and 216,510 deaths due to typhoid fever are reported each year ${ }^{13}$. In endemic areas such as Bangladesh and India, young children under 5 years of age bear a large burden of S. Typhi infection ${ }^{17}$, although it has been suggested that typhoid fever may be less severe in such young children ${ }^{6}$. In reality, the immunological responses and clinical characteristics in young children with $S$. Typhi bacteremia have to date remained poorly characterized. Similarly, it has also been suggested that infection with multi-drug resistant (MDR: resistant to ampicillin, chloramphenicol, trimethoprim

sulfamethoxazole) $S$. Typhi may impact clinical severity and outcome although little is known about MDR $S$. Typhi infection in young children ${ }^{13}$.

However, isolation of the organism takes at least 48-72 hours and the yields is often very low at 40$75 \%$, hence limiting its use to a confirmatory basis only ${ }^{14}$. Widal test has become the most commonly used serologic test in the diagnosis of typhoid fever in endemic areas of the developing world where bacteriologic facilities are lacking ${ }^{15}$. But the test has limitations such as the difficulty in interpretation, the need to demonstrate a four-fold rise after a week and necessity of knowing the endemicity of the $\operatorname{area}^{16}$. So, to avoid prolonged hospital confinement and associated mortalities, there is a need for a rapid diagnostic test that is reliable, simple and economical. Several tests like counter-immunoelectrophoresis and haemagglutination assay ${ }^{17}$ have been developed but none of them gained widespread use because of methodological difficulties.

In the present study a total of 30 Salmonella typhi was isolated with an isolation rate of $12 \%$. Similar 
findings were also reported from Philippines ${ }^{19}$ and from Nigeria ${ }^{20}$ who found an isolation rate of $18.40 \%$ and $10.3 \%$ respectively. Similarly, Asna and $\mathrm{Haq}^{21}$ from Bangladesh reported an isolation rate of $19.2 \%$. Jhora ${ }^{22}$ from Bangladesh reported an isolation rate of $27.5 \%$. The disease affected all ages, however most of the patients $170(68 \%)$ of these study were between 6 to 15 years of age. This finding correlates with the observation made by Jhora $^{22}$ who found that $61.67 \%$ of patients were within 15 years of age. The highest number of patients in this age group was perhaps due to exposure to external environment and practice of taking pre-cooked food from street hawkers ${ }^{11}$.

\section{Conclusion}

In conclusion this study permits to conclude that typhoid fever mostly occurs in the age group of 6 to 15 years. Furthermore, it occurs more commonly among the male than female. Interestingly low income group are mostly suffered from typhoid fever. Further large scale study should be carried out in Bangladesh.

\section{References}

1. Pearson RD, Guerrant RL. Enteric fever and other causes of abdominal symptoms with fever, p. 1136-1150. In: G. L. Mandell, J. E. Bennett, and R. Dolin (ed.), Principles and practice of infectious diseases, 5th ed. Churchill Livingstone, New York, N.Y. 2000

2. Doherty CP, Saha SK, Cutting WA. Typhoid fever, ciprofloxacin and growth in young children. Ann Trop Paediatr 2000;20:297-303

3. Kabra SK, Madhulika, Talati A, Soni N, Patel S, Modi RR. Multi-drug resistant typhoid fever.Trop Doct 2000; 30 :195-197

4. White NJ, Parry CM. The treatment of typhoid fever. Curr Opin Infect Dis 1996;9: 298-302.

5. Myron M, Levine and Vial PA. 1999. Typhoid Fever: In Gell's and KaGan's Current Pediatric Therapy. $16^{\text {th }}$ Ed. Editors: Burg FD, Ward ER, Ingelfinger JR, Polin RA. W.B.Saunders Company, Philadelphia, p-100-106

6. Sen S, Goyal RS, Dev R. 1991. Ciprofloxacin in the management of multi-drug resistant typhoid fever. Ind Paed.28: 417-419

7. Parkhill J, Dougan G, James KD, et al. Complete genome sequence of a multiple drug resistant Salmonella enterica serovar typhi CT18. Nature 2001;413:848-52
8. Ivanoff B, Typhoid fever : global situation and WHO recommendations. Southeast Asian J Trop Med Public Health 1995; 26 : Suppl 2 : 1-6

9. Alam MN, Haq SA, Majid MN, Hasan Z, Ahsan SA, Ahmed N, Rahman KM. Multidrug resistant enteric fever in Bangladesh. Bangladesh J Med 1992;3 : 38-41.

10. Grossman DA, Witham ND, Burr DH, et al. Flagellar serotypes of Salmonella typhi in Indonesia: relationship among motility, invasiveness, and clinical illness. J Infect Dis 1995;171:212-6

11. Sinha A, Sazawal S, Kumar R, Sood S, Reddaiah VP, Singh B et al. Typhoid fever in children aged less than 5 years. Lancet 1999; $354:$ 734-737

12. Saha MR, Dutta P, Niyogi SK, Dutta S, Mitra U, Ramamurthy $\mathrm{T}$ et al. Decreasing trend in the occurance of Salmonella enterica serotype typhi amongst hospitalized children in Kolkata, India during 1990-2000. Indian J Med Res 2002; $115: 46-48$

13. Rahman M, Ahmed A, Shoma S. Decline in epidemic of multidrug resistant Salmonella typhi is not associated with increased incidence of antibiotic - susceptible strain in Bangladesh. Epidemiol Infect 2002; 129 : 29-34

14. Rahman GA, Abubakar AM, Johnson AW, Adeniran JO. Typhoid ilea perforationin Nigerian children : an analysis of 106 operative cases. Pediatr Surg Int 2001; 17 : 628630

15. Saha SK, Baqui AH, Hanif M, Darmstadt GL, Ruhulamin $\mathrm{M}$, Nagatake $\mathrm{T}$ et al. Typhoid fever in Bangladesh: implications for vaccination policy. Pediatr Infect Dis J 2001; $20: 521-524$

16. Swaddiwudhipong W, Kanlayanaphotporn J. A common source water-borne outbreak of multi-grug resistant typhoid fever in a rural Thai community. J Med Assoc Thai 2001; 84: 1513-1517

17. Wain J, Bay PV, Vinh H, Duong NM, Diep TS, Walsh AL et al. Quantitation of bacteria in bone marrow from patients with typhoid fever : relationship between counts and clinical features. J Clin Microbiol 2001;39:1571-1576.

18. Thong K-L, Bhutta ZA, Pang T. Multidrug-resistant strains of Salmonella enterica serotype typhi are genetically homogenous and coexist with antibioticsensitive strains as distinct, independent clones. Int $\mathbf{J}$ Infect Dis 2000;4:194-7.

19. Okoko BJ, Ota MO, Arowolo JO, Whittle HC. Peripheral gangrene complicating Salmonella typhi septicaemia in a Gambian infant. J Trop Pediatr 2001; 47 : 250251.

20. Kariuki S, Gilks C, Revathi G, Hart CA. Genotypic analysis of multidrug resistant Salmonella enterica serovar typhi, Kenya. Emerg Infect Dis 2000;6:649-51.

21. Asna SZ, Haq JA. Decrease of antibiotic resistance in Salmonella typhi isolated from patients attending hospitals of Dhaka City over a 3 year period. International journal of antimicrobial agents. 2000 Nov 30;16(3):249-51

22. Jhora ST. A study on typhoid fever \& sero-diagnosis by Widal, modified Widal \& CIEP methods. [M.Phil. Thesis in Microbiology], IPGMR, Dhaka, Bangladesh, 1995 